\title{
Evidence of the Effectiveness of Pictorial Health Warnings on Cigarette Packaging in Nepal
}

\author{
Tara Singh Bam ${ }^{1 *}$, Ananda B Chand ${ }^{2}$, Bharat V. Shah ${ }^{3}$
}

\begin{abstract}
Background: Tobacco Control Act of 2010 mandates government to implement at least $75 \%$ pictorial health warnings (PHWs) on tobacco packaging that was enforced in 2013. The purpose of the study was to assess the effectiveness of PHWs and its impact to the policy change. Methods: A cross-sectional study was conducted in 9 cities between September 2014 and March 2015. Direct interviews were made among 2250 randomly selected individuals. The effectiveness of PHWs were measured as perceived: i) scariness; ii) quit motivation iii) convincing youth not to start smoking; iv) encouraging ex-smokers to remain as quitters; v) building public awareness. Logistic regression analysis was used to determine the factors associated with the effectiveness of PHWs. Results: Of the 2250 participants, 29.8\% (670) were current smokers, 8.6\% (193) were ex-smokers and 97.6\% believed that smoking was addictive. PHWs made $83 \%$ of the participants scared. Participants believed that PHWs would be effective in motivating smokers to quit (80.2\%), in convincing youth not to start smoking $(86.8 \%)$, in encouraging ex-smokers to remain as quitters $(89.1 \%)$ and in building public awareness on the dangers of smoking (94\%). PHWs made $58 \%$ of the current smokers intended to quit smoking and reduced their daily intake of cigarettes from 11 to 5 on average. Current smokers preferred to purchase loose cigarettes rather than a pack. The covariates significantly associated with the effectiveness of PHWs were current smokers, ex-smokers and addiction. Conclusion: PHWs were found important to motivate smokers to quit smoking, to reduce consumption of cigarettes and to prevent relapse in ex-smokers. Evidence from the study had triggered policy changes which included enlargement of the size of PHW to $90 \%$ and the release of a notification to ban selling of loose cigarettes. Thus, the warning messages with pictures are required to be improved and rotated.
\end{abstract}

Keywords: Pictorial- health- warning- effective- Nepal

Asian Pac J Cancer Prev, 22, Progress of Tobacco Control in the South-East Asia Region Suppl, 35-44

\section{Introduction}

Tobacco usage possesses a serious threat on health. Every year, tobacco kills 24,800 Nepalese, nearly half of them prematurely, and causes the loss of 341,000 years of life. More than 3,500 of these lives lost are due to the exposure to second-hand smoke and $47 \%$ of deaths are among individuals under age 70 (NHEICC, 2019). Nearly $29 \%$ of adults aged $15-69$ years $(48.3 \%$ of men, $11.6 \%$ of women) use some type of tobacco. Two-thirds of people aged 15-69 years were exposed to secondhand smoke on a daily basis (Dhimal et al., 2020).

Nepal signed a World Health Organization Framework Convention on Tobacco Control (WHO FCTC) in 2003 with ratification of the convention in 2006 (UN, 2021). The Tobacco Product (Control and Regulatory) Act was passed in 2010 (GoN, 2011) with a subsequent implementation of a PHWs Directives adopted in 2011 (MOHP, 2011). PHWs composed of both pictures and text and covered $75 \%$ of the upper front, upper back, and two sides of smoked tobacco product packaging and the upper front, upper back, and lids (where appropriate) of smokeless tobacco product packaging.

Larger graphic health warning reduces the attractiveness and appeal of tobacco products to consumers, increases the noticeability and effectiveness of health warnings, and reduces the ability of the tobacco product and its packaging to mislead consumers about the harms of smoking. Effective health warning labels provide direct health messages to smokers, raising awareness of the health risks and increasing the likelihood that they will reduce or quit tobacco use (Hammond et al., 2006). PHW is an extremely cost-effective public health intervention and have tremendous reach. In Nepal, PHW regulation with $75 \%$ coverage on upper part of tobacco packaging was first enforced on December 30, 2013. The current study aimed to assess the effectiveness of PHWs in motivating smokers to quit smoking, convincing youth not to start smoking, encouraging ex-smokers to remain as quitters, and building public awareness on the dangers of tobacco use. 


\section{Materials and Methods}

\section{Study design}

This was a cross-sectional study conducted between September 2014 and March 2015 in 9 districts (Kailali, Banke, Kaski, Chitawan, Parsa, Bhaktapur, Lalitpur, Kathmandu and Morang) of Nepal. Participants of aged 13 years and above were included in the study.

\section{Sample size}

A sample size was calculated using SurveyMonkey software (https://www.surveymonkey.com/mp/ sample-size-calculator/). A population of 26.4 million was taken into account while calculating a sample size with a margin error of $2.1 \%$ at a $95 \%$ confidence level. The required sample size was 2178 individuals. We recruited a sample of 2250 participants in the study.

\section{Sampling frame}

A multistage sampling technique was developed. Step 1: stratification was done as per the regions (FWR $=$ Far Western Region, MWR = Mid-western Region, WR $=$ Western Region, $\mathrm{CR}=$ Central Region, $\mathrm{ER}=$ Eastern Region) with districts and population in each region in 2014. Step 2: districts were selected randomly from each region considering the size of the population. Step 3: District headquarters was selected in each district purposively. Step 4: A simple random method was used to select two public places, two shopping centers, two university campuses, two bus terminals, and three senior high schools from the list made available by the local administration of each city. Step 5: at least 250 participants were recruited randomly from the selected venues of each district.

\section{Data collection}

A direct interview was conducted in the Nepali language by 4 trained surveyors in each district. Once participants provided verbal consent for the interview, either they were interviewed on the spot or an interview was scheduled for another day as preferred by the participants. Interviews were carried out within a week of the agreement. They were followed up by telephone. Participants from university campuses and senior high schools were interviewed on the same day in their locations. A pre-tested semi-structured questionnaire was administered. Study participants were asked whether they saw PHWs on tobacco packs. Surveyors had shown the packs with PHWs to the participants who had not seen the PHWs before. Participants were asked regarding socio-demographic characteristics (age, sex, marital status occupation and education), smoking behavior, and perceived effectiveness of PHW. The interviews took an average of 30 minutes.

\section{Measures}

Five outcome indicators were developed to measure the perceived effectiveness of PHWs. The perceived effectiveness was assessed using a 5-point Likert scale of disagreement with a set of questions where $1=$ '"not effective at all" and $5=$ "'extremely effective'. Key questions included were how effective would PHWs be to motivate smokers to quit smoking? How effective would PHWs be to convince youth not to start smoking? How effective would PHWs be to re-convince ex-smokers to remain quitter? How effective would PHWs be to build public awareness of the dangers of smoking? How effective would PHWs be to scare people into the danger of smoking?

The data were analyzed using IBM SPSS version 20.0 (Statistical Package for the Social Sciences Inc. Chicago, IL, USA). Descriptive, univariate and multivariate logistic regression analyses were conducted. To avoid small cell counts, answers were recoded into the following three categories: very effective (extremely effective and very effective), effective (effective and somewhat effective) and not effective (not effective at all). For the multivariate analysis, answers were recorded using the following two categories: effective (included extremely effective, very effective and somewhat effective) and not effective (included not effective at all). The level of significance was set at $\mathrm{P}<0.05$ for all analyses.

\section{Definitions}

A current smoker was defined as who smokes daily at least one cigarette per day or at least 7 cigarettes per week, an occasional smoker was defined who smokes less than one cigarette per day or less than 7 cigarettes per week. An ex-smoker was defined as a person who used to smoke daily or occasionally but had not smoked in the last 6 months, not even a puff. Never smoking was defined as a person who has never smoked, not even a puff.

\section{Ethical statement}

The study was approved by the Nepal Health Research Council. Verbal informed consent was obtained from study participants. An official approval was received from participating schools in the study. No individual identifiers were provided to individuals outside the study team.

\section{Results}

Table 1 shows the characteristics of the overall study participants and the association of the perceived effectiveness of PHWs with sub-groups of demographic characteristics. The median age of participants was 23 years. Of the 2,250 participants, $76 \%$ were males, $51.9 \%$ were students, $87 \%$ had a high school degree or above, $29.8 \%$ (670) were current smokers, and 8.6\% (193) were ex-smokers. Almost all (97.6\%) participants believed smoking was addictive.

\section{Perceived scariness of PHWS}

Overall, $43.9 \%$ of the participants perceived PHWs were very scary and only $17 \%$ perceived the warnings were not scary (Table 1). Females were more likely to be scared compared with males ( $\mathrm{aOR}=0.47,95 \%$ $\mathrm{CI}=0.33-0.67)$. Participants who believed smoking was addictive were more likely to be scared than those who did not $(\mathrm{aOR}=2.24,95 \% \mathrm{CI}=1.21-4.13)$. Current smokers $(\mathrm{aOR}=2.16,95 \% \mathrm{CI}=1.38-3.36)$ and ex-smokers $(\mathrm{aOR}$ $=1.99,95 \% \mathrm{CI}=1.54-2.57$ ) were significantly associated 


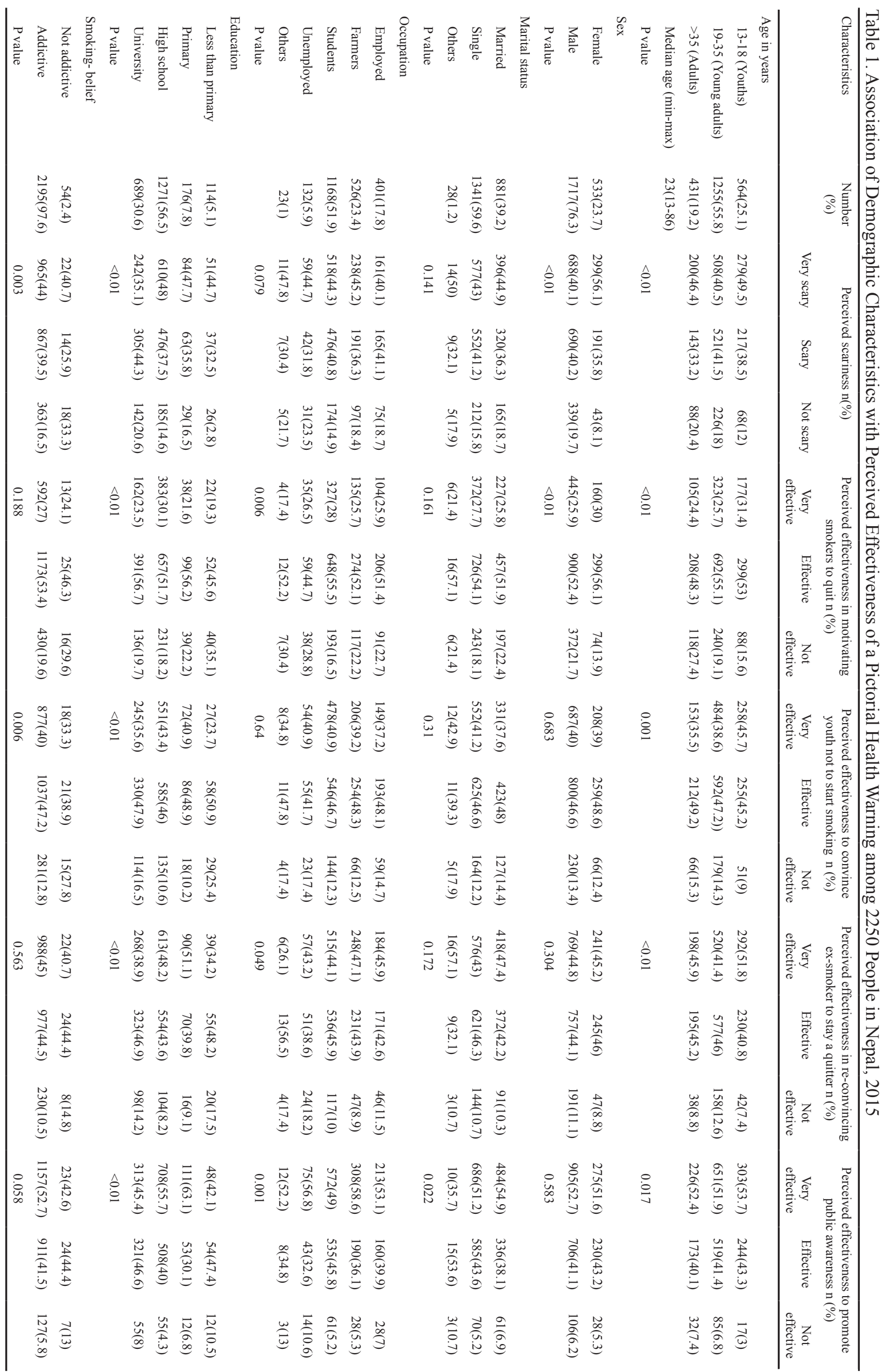




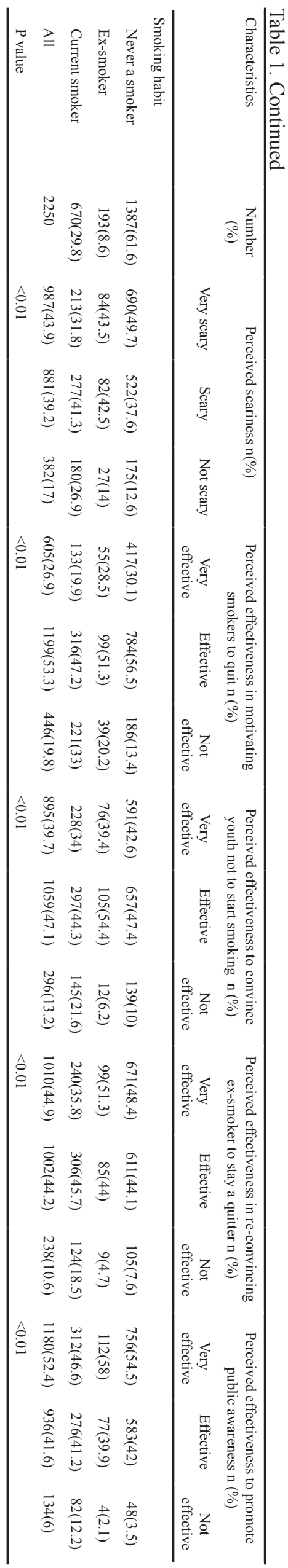

with perceived scariness to the PHWs (Table 2).

Perceived effectiveness of PHWs motivating smokers to quit

PHWs were found very effective by over a quarter $(26.9 \%)$ and effective by more than half $(53.3 \%)$ of the participants in motivating smokers to quit (Table 1). Current smokers $(\mathrm{aOR}=1.94,95 \% \mathrm{CI}=1.31-2.87)$ and ex-smokers $(\mathrm{aOR}=2.92,95 \% \mathrm{CI}=2.26-3.77)$ were found to be more likely than those who never smoked to perceive that the PHW would be effective in motivating smokers to quit smoking (Table 3). Current smokers particularly were asked about any change in smoking behaviour due to PHW on tobacco packs. It was reported that PHW made $58 \%$ of the current smokers think to quit smoking (Figure 1a) and made the current smokers reduce cigarettes smoked per day up to $55 \%$ (from 11 cigarettes per day to 5 cigarettes per day) after implementation of a $75 \%$ pictorial health warning (Figure 1b).

Perceived effectiveness of PHW in convincing youth not to start smoking

About $40 \%$ of the participants perceived that PHWs were very effective in convincing youth not to start smoking (Table 1). It was found more effective among

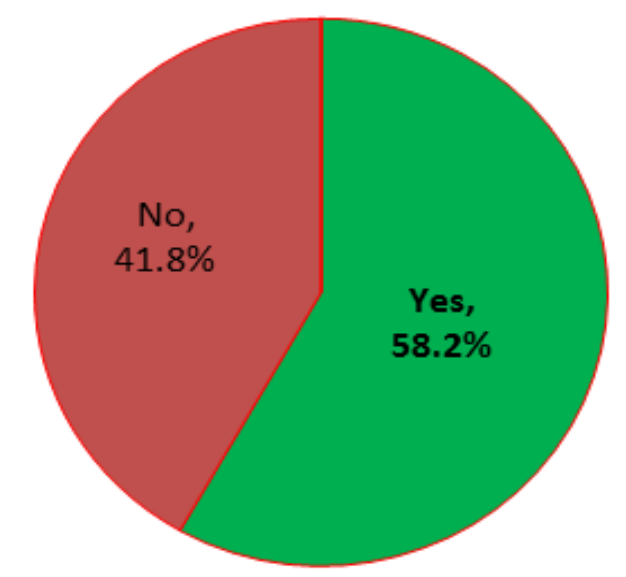

Figure 1a. Current Smokers' Intention to Quit Smoking because of PHW (current smokers $=670$ )

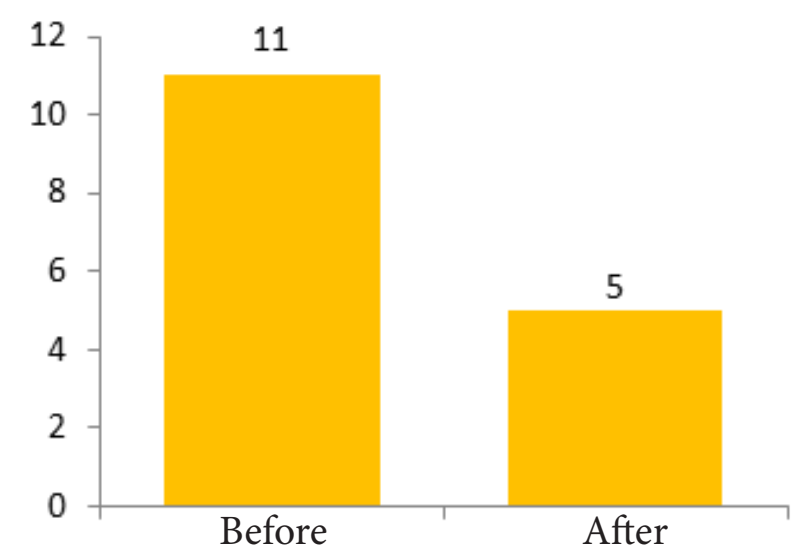

Figure 1b. Changes in Behaviour of Current Smokers in Number of Cigarettes Smoked Per Day before and after PHW Implementation (current smokers $=670$ ) 


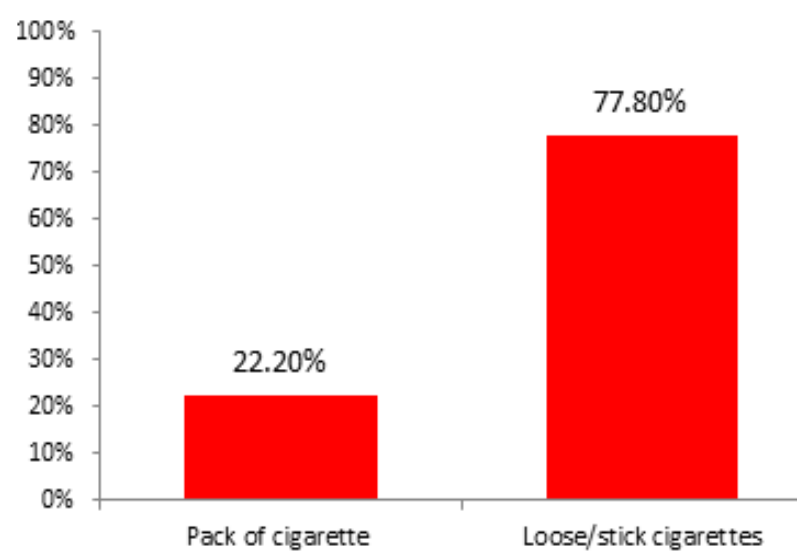

Figure 1c. Changes in Practice of the Current Smokers to Buy Cigarettes either a Pack or Sticks after Implementation of PHW (current smokers $=670$ )

those who had primary $(\mathrm{aOR}=1.95,95 \% \mathrm{CI}=1.16-3.27)$ and less than primary $(\mathrm{aOR}=2.50,95 \% \mathrm{CI}=1.29-4.86)$ education compared to those with high school and above. Current smokers $(\mathrm{aOR}=3.93,95 \% \mathrm{CI}=2.12-7.27)$, ex-smokers $(\mathrm{aOR}=2.29,95 \% \mathrm{CI}=1.74-2.99)$ and participants who thought smoking was addictive (aOR $2.03,95 \% \mathrm{CI}=1.06-3.89$ ) were more likely to perceive the effectiveness of PHWs in convincing youth not to start smoking (Table 4). Over $90 \%$ of the youth aged 13 to 18 years reported PHW was effective in discouraging them to start smoking (figure 1d).

Perceived effectiveness of PHWs in re-convincing ex-smokers to remain quitters

Approximately $90 \%$ of the participants perceived that PHWs were effective (44.9\% very effective, $44.2 \%$ effective) in re-convincing ex-smokers to remain

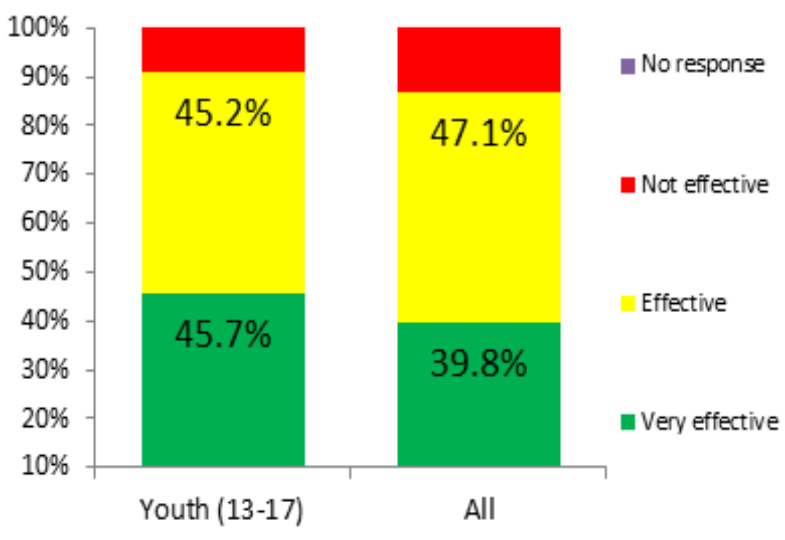

Figure 1d. Perceived Effectiveness of PHW Discouraging Youth to Start Smoking $(\mathrm{N}=2250$, youth $=504)$

quitters (Table 1). Participants with primary $(\mathrm{aOR}=$ $2.26,95 \% \mathrm{CI}=1.24-4.11)$ and less than primary $(\mathrm{aOR}=$ 2.06 (1.01-4.31) education were more likely to be associated with the perceived effectiveness of PHW. Current smokers $(\mathrm{aOR}=4.35,95 \% \mathrm{CI}=2.15-8.77)$ and ex-smokers $(\mathrm{aOR}=2.73,95 \% \mathrm{CI}=2.02-3.69)$ were more likely to perceive that the PHWs would be effective in re-convincing ex-smokers to remain quitters (Table 5).

\section{Perceived effectiveness of $\mathrm{PHW}$ in promoting public} awareness

More than half (52.4\%) of the respondents perceived that PHW would be very effective in promoting public awareness (Table 1). Current smokers $(\mathrm{aOR}=6.68$, $95 \% \mathrm{CI}=2.40-18.58)$ were 6 times and ex-smokers were 3 times $(\mathrm{aOR}=3.63,95 \% \mathrm{CI}=2.44-5.39)$ more likely to perceive that the PHWs would be effective in promoting

Table 2. Logistic Regression Analysis to Determine Factors Associated with the Perceived Scariness of PHWs

\begin{tabular}{|c|c|c|c|c|}
\hline Factor & Number & Perceived scariness n $(\%)$ & OR $(95 \% \mathrm{CI})$ & $\mathrm{aOR}(95 \% \mathrm{CI})$ \\
\hline \multicolumn{5}{|l|}{ Age in years } \\
\hline >35 (Adults-reference) & 431 & $343(79.6)$ & 1 & 1 \\
\hline 19-35 (Young adults) & 1,255 & $1029(82)$ & $0.53(0.38-0.76)$ & $0.81(0.55-1.19)$ \\
\hline 13-18 (Youths) & 564 & $496(87.9)$ & $0.62(0.47-0.84)$ & $0.95(0.68-1.33)$ \\
\hline \multicolumn{5}{|l|}{ Sex } \\
\hline Female (reference) & 533 & $490(91.9)$ & 1 & 1 \\
\hline Male & 1,717 & $1378(80.3)$ & $0.36(0.26-0.49)$ & $0.47(0.33-0.67)$ \\
\hline \multicolumn{5}{|l|}{ Education } \\
\hline University (reference) & 689 & $547(79.4)$ & 1 & 1 \\
\hline High school & 1,271 & $1086(85.4)$ & $1.14(0.71-1.83)$ & $0.80(0.47-1.37)$ \\
\hline Primary & 176 & $147(83.5)$ & $1.73(1.09-2.76)$ & $1.17(0.70-1.96)$ \\
\hline Less than primary & 114 & $88(77.2)$ & $1.49(0.83-2.70)$ & $1.32(0.72-2.44)$ \\
\hline \multicolumn{5}{|l|}{ Smoking addiction } \\
\hline Believe not addictive (reference) & 54 & $36(66.7)$ & 1 & 1 \\
\hline Believe addictive & 2,195 & $1832(83.5)$ & $2.52(1.42-4.49)$ & $2.24(1.21-4.13)$ \\
\hline \multicolumn{5}{|l|}{ Smoking habit } \\
\hline Never a smoker (reference) & 1,387 & $1212(87.4)$ & 1 & 1 \\
\hline Ex-smoker & 193 & $166(86)$ & $2.54(2.02-3.21)$ & $1.99(1.54-2.57)$ \\
\hline Current smoker & 670 & $490(73.1)$ & $2.26(1.45-3.51)$ & $2.16(1.38-3.36)$ \\
\hline
\end{tabular}

OR, odds ratio; aOR, adjusted odds ratio; $\mathrm{CI}$, confidence interval 
Table 3. Logistic Regression Analysis to Determine Factors Associated with Perceived Effectiveness of a PHW in Motivating Smokers to Quit Smoking

\begin{tabular}{|c|c|c|c|c|}
\hline Factor & Number & Effective in motivating smokers to quit $\mathrm{n}(\%)$ & OR $(95 \% \mathrm{CI})$ & $\mathrm{aOR}(95 \% \mathrm{CI})$ \\
\hline \multicolumn{5}{|l|}{ Age in years } \\
\hline$>35$ (Adults-reference) & 431 & $313(72.6)$ & 1 & 1 \\
\hline 19-35 (Young adults) & 1,255 & $1015(80.9)$ & $0.49(0.36-0.67)$ & $0.86(0.55-1.33)$ \\
\hline 13-18 (Youths) & 564 & $476(84.4)$ & $0.78(0.59-1.02)$ & $1.16(0.82-1.65)$ \\
\hline \multicolumn{5}{|l|}{ Sex } \\
\hline Female (reference) & 533 & $459(86.1)$ & 1 & 1 \\
\hline Male & 1,717 & $1345(78.3)$ & $0.58(0.45-0.76)$ & $0.89(0.66-1.21)$ \\
\hline \multicolumn{5}{|l|}{ Education } \\
\hline University (reference) & 689 & $553(80.3)$ & 1 & 1 \\
\hline High school & 1271 & $1040(81.8)$ & $2.19(1.43-3.37)$ & $1.36(0.82-2.25)$ \\
\hline Primary & 176 & $137(77.8)$ & $2.43(1.62-3.67)$ & $1.55(0.98-2.46)$ \\
\hline Less than primary & 114 & $74(64.9)$ & $1.90(1.12-3.21)$ & $1.64(0.94-2.84)$ \\
\hline \multicolumn{5}{|l|}{ Occupation } \\
\hline Employed (reference) & 401 & $310(77.3)$ & 1 & 1 \\
\hline Farmers & 526 & $409(77.8)$ & $1.49(0.59-3.73)$ & $1.30(0.50-3.37)$ \\
\hline Students & 1,168 & $975(83.5)$ & $1.53(0.62-3.81)$ & $1.37(0.53-3.51)$ \\
\hline Unemployed & 132 & $94(71.2)$ & $2.21(0.89-5.44)$ & $1.34(0.52-3.52)$ \\
\hline Others & 23 & $16(69.6)$ & $1.08(0.41-2.84)$ & $1.03(0.38-2.79)$ \\
\hline \multicolumn{5}{|l|}{ Smoking habit } \\
\hline Never a smoker (reference) & 1,387 & $1201(86.6)$ & 1 & 1 \\
\hline Ex-smoker & 193 & $154(79.8)$ & $3.18(2.54-3.97)$ & $2.92(2.26-3.77)$ \\
\hline Current smoker & 670 & $449(67)$ & $1.94(1.32-2.86)$ & $1.94(1.31-2.87)$ \\
\hline
\end{tabular}

public awareness on the dangers of smoking among the general population (Table 6).
Smokers' behaviors in purchasing cigarettes after implementation of $\mathrm{PHW}$

Of the 670 current smokers, $77.8 \%$ of them purchased loose/sticks cigarettes and only $22.2 \%$ purchased a pack of cigarettes in their last purchase (Figure 1c).

Table 4. Logistic Regression Analysis to Determine Factors Associated with the Perceived Effectiveness of a PHW in Convincing Youth not to Start Smoking

\begin{tabular}{|c|c|c|c|c|}
\hline $\mathrm{N}$ & Number & $\begin{array}{c}\text { Effective in convincing youth not } \\
\text { to start smoking } \mathrm{n}(\%)\end{array}$ & OR $(95 \% \mathrm{CI})$ & $\mathrm{aOR}(95 \% \mathrm{CI})$ \\
\hline \multicolumn{5}{|l|}{ Age in years } \\
\hline$>35$ (Adults-reference) & 431 & $365(84.7)$ & 1 & 1 \\
\hline 19-35 (Young adults) & 1,255 & $1076(85.7)$ & $0.55(0.37-0.81)$ & $0.85(0.54-1.33)$ \\
\hline 13-18 (Youths) & 564 & $513(91)$ & $0.59(0.43-0.83)$ & $0.91(0.62-1.32)$ \\
\hline \multicolumn{5}{|l|}{ Education } \\
\hline University (reference) & 689 & $575(83.5)$ & 1 & 1 \\
\hline High school & 1,271 & $1136(89.4)$ & $1.72(1.07-2.75)$ & $1.23(0.71-2.11)$ \\
\hline Primary & 176 & $158(89.8)$ & $2.87(1.82-4.54)$ & $1.95(1.16-3.27)$ \\
\hline Less than primary & 114 & $85(74.6)$ & $3.00(1.57-5.71)$ & $2.50(1.29-4.86)$ \\
\hline \multicolumn{5}{|l|}{ Smoking addiction belief } \\
\hline Not addictive (reference) & 54 & $39(72.2)$ & 1 & 1 \\
\hline Addictive & 2,195 & $1914(87.2)$ & $2.62(1.43-4.81)$ & $2.03(1.06-3.89)$ \\
\hline \multicolumn{5}{|l|}{ Smoking habit } \\
\hline Never a smoker (reference) & 1,387 & $1248(90)$ & 1 & 1 \\
\hline Ex-smoker & 193 & $181(93.8)$ & $2.48(1.92-3.19)$ & $2.29(1.74-2.99)$ \\
\hline Current smoker & 670 & $525(78.4)$ & $4.12(2.26-7.69)$ & $3.93(2.12-7.27)$ \\
\hline
\end{tabular}

OR, odds ration; aOR, adjusted odds ratio; $\mathrm{CI}$, confidence interval 
DOI:10.31557/APJCP.2021.22.S2.35

Evidence of the Effectiveness of Pictorial Health Warnings on Cigarette Packaging in Nepal

Table 5. Logistic Regression Analysis to Determine the Factors Associated with the Perceived Effectiveness of a PHW in re-Convincing ex-Smokers to Remain Quitters

\begin{tabular}{|c|c|c|c|c|}
\hline Factor & Number & $\begin{array}{l}\text { Effective in re-convincing ex-smokers to } \\
\text { remain quitters } \mathrm{n}(\%)\end{array}$ & OR $(95 \% \mathrm{CI})$ & $\mathrm{aOR}(95 \% \mathrm{CI})$ \\
\hline \multicolumn{5}{|l|}{ Age in years } \\
\hline >35 (Adults-reference) & 431 & $393(91.2)$ & 1 & 1 \\
\hline 19-35 (Young adults) & 1,255 & $1097(87.4)$ & $0.83(0.52-1.31)$ & $1.54(0.83-2.83)$ \\
\hline 13-18 (Youths) & 564 & $522(92.6)$ & $0.56(0.39-0.79)$ & $0.93(0.59-1.47)$ \\
\hline \multicolumn{5}{|l|}{ Education } \\
\hline University (reference) & 689 & $591(85.8)$ & 1 & 1 \\
\hline High school & 1,271 & $1167(91.8)$ & $1.28(0.75-2.17)$ & $1.32(0.70-2.49)$ \\
\hline Primary & 176 & $160(90.9)$ & $2.38(1.41-4.02)$ & $2.26(1.24-4.11)$ \\
\hline Less than primary & 114 & $94(82.5)$ & $2.12(1.05-4.30)$ & $2.06(1.01-4.31)$ \\
\hline \multicolumn{5}{|l|}{ Occupation } \\
\hline Employed (reference) & 401 & $355(88.5)$ & 1 & 1 \\
\hline Farmers & 526 & $479(91.1)$ & $1.62(0.53-4.98)$ & $1.72(0.54-5.47)$ \\
\hline Students & 1,168 & $1051(90)$ & $2.14(0.70-6.57)$ & $2.11(0.67-6.66)$ \\
\hline Unemployed & 132 & $108(81.8)$ & $1.89(0.63-5.65)$ & $1.70(0.53-5.43)$ \\
\hline Others & 23 & $19(82.6)$ & $0.94(0.29-3.03)$ & $0.99(0.29-3.28)$ \\
\hline \multicolumn{5}{|l|}{ Smoking habit } \\
\hline Never a smoker (reference) & 1,387 & $1282(92.4)$ & 1 & 1 \\
\hline Ex-smoker & 193 & $184(95.3)$ & $2.77(2.09-3.66)$ & $2.73(2.02-3.69)$ \\
\hline Current smoker & 670 & $546(81.5)$ & $4.64(2.31-9.32)$ & $4.35(2.15-8.77)$ \\
\hline
\end{tabular}

OR, odds ratio; aOR, adjusted odds ratio; $\mathrm{CI}$, confidence interval

Table 6. Logistic Regression Analysis to Determine Factors Associated with the Perceived Effectiveness of a PHW in Building Public Awareness on the Dangers of Smoking

\begin{tabular}{|c|c|c|c|c|}
\hline Factor & Number & $\begin{array}{c}\text { Effective in building public awareness } \\
\mathrm{n}(\%)\end{array}$ & OR $(95 \% \mathrm{CI})$ & $\mathrm{aOR}(95 \% \mathrm{CI})$ \\
\hline \multicolumn{5}{|l|}{ Age in years } \\
\hline >35 (Adults-reference) & 431 & $399(92.6)$ & 1 & 1 \\
\hline 19-35 (Young adults) & 1,255 & $1170(93.2)$ & $0.38(0.21-0.70)$ & $0.68(0.29-1.56)$ \\
\hline 13-18 (Youths) & 564 & $547(97)$ & $0.42(0.25-0.72)$ & $0.71(0.37-1.36)$ \\
\hline \multicolumn{5}{|l|}{ Marital status } \\
\hline Married & 881 & $820(93.1)$ & 1 & 1 \\
\hline Single & 1,341 & $1271(94.8)$ & $1.61(0.47-5.49)$ & $1.70(0.46-6.29)$ \\
\hline Others & 28 & $25(89.3)$ & $2.17(0.64-7.39)$ & $2.35(0.63-8.69)$ \\
\hline \multicolumn{5}{|l|}{ Education } \\
\hline University (reference) & 689 & $634(92)$ & 1 & 1 \\
\hline High school & 1,271 & $1216(95.7)$ & $1.35(0.70-2.62)$ & $0.94(0.42-2.10)$ \\
\hline Primary & 176 & $164(93.2)$ & $2.60(1.34-5.01)$ & $1.56(0.74-3.32)$ \\
\hline Less than primary & 114 & $102(89.5)$ & $1.60(0.69-3.71)$ & $1.26(0.52-3.05)$ \\
\hline \multicolumn{5}{|l|}{ Occupation } \\
\hline Employed (reference) & 401 & $373(93)$ & 1 & 1 \\
\hline Farmers & 526 & $498(94.7)$ & $1.99(0.56-7.13)$ & $2.01(0.53-7.60)$ \\
\hline Students & 1,168 & $1107(94.8)$ & $2.66(0.74-9.51)$ & $2.57(0.68-9.63)$ \\
\hline Unemployed & 132 & $118(89.4)$ & $2.72(0.78-9.41)$ & $1.38(0.35-5.45)$ \\
\hline Others & 23 & $20(87)$ & $1.26(0.33-4.79)$ & $1.27(0.31-5.11)$ \\
\hline \multicolumn{5}{|l|}{ Smoking habit } \\
\hline Never a smoker (reference) & 1,387 & $1339(96.5)$ & 1 & 1 \\
\hline Ex-smoker & 193 & $189(97.9)$ & $3.89(2.68-5.62)$ & $3.63(2.44-5.39)$ \\
\hline Current smoker & 670 & $588(87.8)$ & $6.58(2.38-18.21)$ & $6.68(2.40-18.58)$ \\
\hline
\end{tabular}

OR, odds ratio; aOR, adjusted odds ratio; $\mathrm{CI}$, confidence interval 


\section{Discussion}

Our findings suggest that PHWs on tobacco package was perceived effective in the five following ways: i) inducing scariness; ii) convincing smokers to quit; iii) convincing youth not to take up smoking; iv) re-convincing ex-smokers to remain quitters; and v) promoting public awareness on the dangers of tobacco use among the general population. The evidence suggests that PHWs on tobacco packs are effective and they are cost-effective means of communication and information sharing at the population level.

\section{Perceived scariness of PHWs}

Without any doubt, it is evident that PHWs on tobacco packaging are effective means of communication that carries hard-hitting self-explanatory information about the health risks of smoking in any segment of the population. PHWs on cigarette packs was noticed by almost all current smokers $(99.3 \%), 95.9 \%$ of the ex-smokers and $90.9 \%$ of the never smokers as presented in our study. The 2019 NCD STEPS survey in Nepal also showed a higher proportion $(75.7 \%)$ of adults who noticed the health warning on tobacco packages (Dhimal et al., 2020). Studies published in the last decade continue to show that the introduction of stronger health warnings results in warnings being more frequently noticed and read (Scollo, et al., 2019). Our study has shown an association with the perceived scariness of PHW among current smokers, ex-smokers and people who believed smoking was addiction, which might be partly due to frequent exposure to PHW on tobacco packs, as the addiction is attributable to push smokers for frequent smoking. These results reinforce the fact that it is the first thing observed when buying the package and the last thing observed before lighting up by the smokers (Kaiserman, 1993).

\section{Perceived effectiveness of PHW motivating smokers to quit}

Our study documented that PHW would be effective to convince smokers to quit smoking. Moreover, 58\% of the current smokers were found more likely to be convinced to quit smoking when they first came out in 2013. After 5 years of introduction of PHW, the findings of the 2019 NCD STEPS survey present about $45 \%$ of current tobacco users thought of quitting because of the large health warnings (Dhimal et al., 2019). PHWs appear to drop some, but not all, of their effectiveness as smokers become used to seeing the pictures on the packs. Negative emotions elicited by health warnings encourage behaviour change, promoting attention to warnings and behavioural responses that positively predict quit attempts (Scollo et al., 2019). Other published studies have shown similar results regarding the effectiveness of PHWs for educating smokers concerning the health risks of smoking and increasing smokers' knowledge concerning these health risks and motivating smokers to quit smoking (Hammond et al., 2006; Borland et al., 2009; Li and Grigg, 2009). Our study also presents that PHW made the current smokers reduce the number of cigarettes smoked per day to 5 on average compared to 11 cigarettes smoked per day before the implementation of PHW. Reports of the NCD STEPS survey also revealed almost the same data that the average number of cigarettes smoked per month per smoker was 151 that was equivalent to 5 cigarettes per day (Dhimal et al., 2019). Scollo and colleagues noted that study conducted in 2018, 52\% of Australian smokers reported that the enhanced graphic health warnings introduced in 2012 made them think about quitting and a survey of 1,500 smokers conducted in Pakistan in 2014 reported 32\% of smokers attempted to quit following introduction of graphic health warnings (Scollo et al., 2019). Other studies concluded that the stronger the warnings, the greater the reactions, and thus the greater the quitting activity they evoke (Borland et al., 2009). These findings demonstrated that larger pictorial health warnings are powerful in warning smokers about the danger of smoking. The warning messages with pictures are required to improve and refreshed.

\section{Perceived effectiveness of PHW in convincing youth not} to start smoking

Our findings revealed that PHW would be effective in convincing youth not to start smoking. More than $90 \%$ of the youth aged 13 to 18 years reported that PHW discouraged them to start smoking. Similar results were presented in published studies in other countries. In a national survey in the United Kingdom, $90 \%$ of youth nonsmokers reported that warnings had put them off smoking (Moodie et al, 2009). Study's findings from 27 European Union (EU) member states and Norway found that three out of ten non-smokers reported that health warnings had been effective in discouraging them from smoking (EU, 2009). Studies from Nigeria and Lebanon as reported by Scollo and colleagues suggest that PHWs would prevent youth from initiating smoking and intention to quit (Scollo et al., 2019). Published studies showed that between one-fifth and two-thirds of youth non-smokers indicated that health warnings had helped prevent them from taking up smoking in Canada and Australia (Hammond, 2011; Shanahan P., 2009). Thus, PHW is an effective tool for encouraging non-smokers, including youth, not to start smoking

\section{Perceived effectiveness of PHWs in re-convincing ex-smokers to remain quitters}

Our findings have shown that ex-smokers were more likely to report the perceived effectiveness of PHWs in re-convincing them to remain quitters suggesting that exposure to PHWs might have an increased likelihood of the awareness on health risks. A study with former smokers from Australia, Canada, the UK and the USA has shown that health warnings can reduce the odds of a smoking relapse, because they may remind former smokers of the reasons they had for quitting (Partos et al., 2012).

\section{Perceived effectiveness of $\mathrm{PHW}$ in promoting public awareness}

Our study has shown that the effectiveness of PHWs does not differ by age, sex, marital status, educations and occupation in building public awareness on danger of smoking, suggesting that it attributes to easier access to information available with smokers most of the time. 
Published studies suggest that PHWs increase smokers' knowledge about the health hazards of tobacco smoking (Hammond et al., 2006) and they capture attention and contribute to memorizing information for a longer time (Strasser et al., 2012). PHWs are a direct and cost-effective means of communication because they reach every smoker and have a continuous impact as smokers are confronted with a warning message every time, they have a pack in their hands (Sambrook Research International, 2009). Therefore, PHWs on cigarette packages are an important means of health education and communication.

\section{Smokers' behaviors in purchasing cigarettes after implementation of $\mathrm{PHWS}$}

Our study findings revealed that current smokers more likely to change their practice to purchase loose or sticks forms of cigarettes instead of a pack of cigarettes after the introduction of PHW on tobacco packs. It suggests the credibility of PHWs to make smokers scared by communicating the health risk of smoking. The findings also suggest improving tobacco control regulation to ban the sale of single stick or loose cigarettes to further strengthen the effect of PHW on tobacco packs.

Our study has several strengths. This was the first study so far conducted in Nepal to measure the effectiveness of PHWs. Almost all major cities of Nepal were included in the study, from the far west to the eastern parts of Nepal. The key questions included in the questionnaire have been already used in other countries such as Myanmar, Indonesia, and Cambodia. The study does, however, have some possible limitations. Information was largely obtained through interviews, and there might be some recall bias in the responses. The introduction of a PHW is a new intervention in Nepal. Participants might have responded to the effectiveness of a PHW with enthusiasm, which might have led to overestimating the effect.

In conclusion, Tobacco Control Act 2010, which included PHWs as one of the key measures to reduce tobacco-related morbidity and mortality in Nepal. The evidence presented in this study demonstrated that PHWs are effective in building public awareness, motivating smokers to build quit intentions, convincing youth not to start smoking, and re-convincing ex-smokers to remain quitters. The preliminary results of the study inspired the Ministry of Health and Population to make extraordinary progress in increasing the size of PHW from 75\% to $90 \%$ with effective in June 2015 (MOHP, 2014). Further in 2016, the study results contributed to the Government of Nepal to release an enforcement notification of article 11 (4) of the tobacco control law 2010 regarding the ban of selling single sticks of cigarettes, cigars and bidi. Our study strongly suggests that larger PHWs on the cigarette packs would have larger visibility, credibility and the ability to convey the right messages directly to the right people at right time. PHWs are more likely to create cessation, prevent the initiation of smoking in youth and prevent relapse in ex-smokers. Therefore, PHWs are one of the best-buys recommended by WHO that contribute to reducing tobacco use.

\section{Author Contribution Statement}

The authors confirm contribution to the paper as follows: study conception and design: Tara Singh Bam, Ananda B Chand; data collection: Ananda B Chand, Bharat V. Shah; analysis and interpretation of results: Tara Singh Bam, Ananda B Chand, Bharat V. Shah; draft manuscript preparation: Tara Singh Bam. All authors reviewed the results and approved the final version of the manuscript.

\section{Acknowledgements}

The authors thank; Bostan International College in helping with data collection, Tanup S Bam for editing English and the Bloomberg Philanthropies for financial assistant for the study.

The publishing cost was provided by WHO office in South-East Asia.

Statement conflict of interest

Authors declared no potential conflict of interest.

\section{References}

Borland R, Wilson N, Fong GT, et al (2009). Impact of graphic and text warning on cigarette packs: findings from four countries over five years. Tob Control, 18, 358-64.

Dhimal M, Bista B, Bhattarai S, et al (2020). Report of Non Communicable Disease Risk Factors: STEPS Survey Nepal 2019. Kathmandu: Nepal Health Research Council. Available at: https://www.who.int/docs/default-source/ nepal-documents/ncds/ncd-steps-survey-2019-compressed. pdf?sfvrsn=807bc4c6_2 [Accessed on 2 June 2021].

European Commission (2009). Eurobarometer: Survey on tobacco (analytical report). 2009. Available from: http:// ec.europa.eu/public_opinion/flash/fl_253_en.pdf [accessed on 22 June 2021].

Government of Nepal (2010). Tobacco (Control and Regulatory) Act 2010. Available at https:/www.tobaccocontrollaws.org/ files/live/Nepal/Nepal\%20-\%20TPA.pdf . [Accessed on 16 June 2021].

Hammond D, Fong GT, McNeill A, et al (2006). Effectiveness of cigarette warning labels in informing smokers about the risks of smoking: findings from the International Tobacco Control (ITC) Four Country Survey. Tob Control, 15, 19-25.

Hammond D (2011). Health warning messages on tobacco products: A review. Tob Control, 20, 327-37.

Kaiserman MJ (1993). The effectiveness of health warning messages. Tob Control, 2, 267.

Li J, Grigg M (2009). New Zealand: new graphic warnings encourage registrations with the quitline. Tob Control, 18, 72 .

Ministry of Health and Population (2011). Directives for Printing and Labelling of Warning Message and Picture in the Box, Pocket, Wrapper, Carton, Parcel and Packaging of Tobacco Product 2011. Available at https://www.tobaccocontrollaws. org/files/live/Nepal/Nepal\%20-\%20PL\%20Directive.pdf [Accessed on 27 May 2021].

Ministry of Health and Population, (2014). Directives for Printing and Labelling of Warning Message and Picture in the Box, Pocket, Wrapper, Carton, Parcel and Packaging of Tobacco Product 2014. Ministry of Health and Population, Kathmandu, Nepal. Available on https:// www.tobaccocontrollaws.org/legislation/country/nepal/laws 
[Accessed on 25 June 2021].

Moodie C, Mackintosh A, Hammond D (2009). Adolescents' response to text-only tobacco health warnings: Results from the 2008 UK youth Tobacco policy survey. Eur J Public Health, 20, 463-9.

National Health Education Information and Communication Centre, (2019). Investment Case For Tobacco Control in Nepal, The Case for Investing in WHO FCTC Implementation 2019.

Partos TR, Borland R, Yong HH, et al (2012). Cigarette packet warning labels can preventrelapse: findings from the International Tobacco Control 4-Country policy evaluation cohort study. Tob Control, Available at http://dx.doi. org/10.1136/tobaccocontrol-2011-050254 [Accessed on 24 June 2021].

Sambrook Research International (2009). A review of the science base to support the development of health warnings for tobacco packages. Prepared for European Commission, Directorate General for Health and Consumers, http:// ec.europa.eu/health/tobacco/docs/warnings_report_en.pdf (accessed on 18 June 2021).

Scollo M, Hippolyte, Miller C (2019). Evidence about the effects of health warnings. In Scollo, MM and Winstanley, MH [editors]. Tobacco in Australia: Facts and issues. Melbourne: Cancer Council Victoria; 2019. Available from: https://www. tobaccoinaustralia.org.au/chapter-12-tobacco-products/ attachment-12-1-health-warnings/12a-3-evidence-abouteffects-of-health-warnings. [Accessed on 21 June 2021].

Shanahan P, Elliott D (2021). Evaluation of the effectiveness of the graphic health warnings on tobacco product packaging 2008. Canberra, Australia: Australian Government Department of Health and Ageing, 2009. Available from: http://webarchive.nla.gov.au/gov/20140801094931/http:// www.health.gov.au/internet/main/publishing.nsf/Content/ phd-tobacco-eval-graphic-health-warnings-exec-sum. [Accessed on 18 June 2021].

Strasser AA, Tang KZ, Romer D, et al (2012). Graphic warning labels in cigarette advertisements: recall and viewing patterns. Am J Prev Med, 43, 41-7.

United Nations (2021). Status of Treaties, WHO Framework Convention on Tobacco Control. Available at, https://treaties. un.org/pages/ViewDetails.aspx?src=TREATY\&mtdsg no $=$ IX- $4 \&$ chapter $=9 \&$ clang $=$ en. $[$ Accessed on 15 June 2021].

\section{c) (7) (8)}

This work is licensed under a Creative Commons AttributionNon Commercial 4.0 International License. 